\title{
Cinco cuentos inconclusos (más)
}

\author{
- José Luis Androde Guzmón
}

Para N. M.

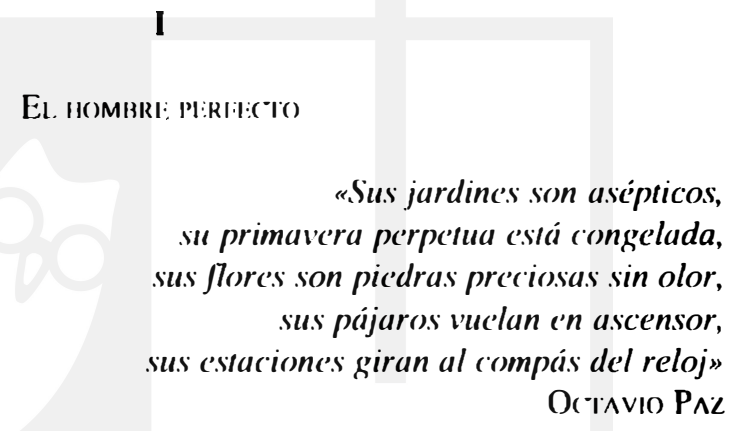

Por fin tenía ante sí al hombre de sus sueños. Su rechazo visceral a todo aquello que revelara la corrupción física a la que inexorablemente están condenados los humanos - sudores, olores, arrugas, manchas, llagas, barros o espinillas- la había llevado a una húsqueda obsesiva por la perfección física, la silueta bien delineada, la piel suave y lisa, el cuerpo limpio y sin rastros de transpiración. El hombre de sus sueños tenía que ser así: absolutamente pulcro e incontaminado, sin más olor que el que dejaran en su cuerpo las fragancias y perfumes más exquisitos, sin el menor rastro de deterioro o descomposición corporal, totalmente higićnico y asćptico. Desde que tuvo conciencia de lo que significaha ser mujer supo que ese sería el objetivo más importante de su vida; que no descansaría hasta ver realizado su propósito de hallar al hombre perfecto. Ahora se podia sentir plenamente satisfecha, pues habia encontrado al ser que materializaba su ideal de perfección masculina: un maniquí. 
Voy por tu cuerpo como por al mundo, tu vienere e's una plaza soléada. aus pechos dos iglesias donde oficia la sangre sus misterios paralelos

() (TAVIO PA\%

Apenas emitió un leve quejido cuando ella corló de raíz. sus genitales. Lo más difícil fue la primera puñalada en la boca del estómago: fue también la más dolorosa. La frialdad del metal caló en lo profundo de sus entrañas, sintió cómo sus inlestinos se retorcían lucgo de ser atravesados por el liloso acero, lodo su cuerpo fue presa de un vértigo que le impidió pensar en algo que no luera el agudo dolor que brotaba del eentro de su ser. Eilla lenía la muerte en la mirada. Tras la segunda puñalada, esa fue su mayor cerleza. Se esforzó por hallar una explicación a lo que sucedía, pero fue en vano. Estaba seguro de haberle dado todo lo que clla había pedido, sin importar cuán inacessibles fueran sus deseos. Como un eco lejano, sintió una estocada más en su pecho. No pudo ver su corazón retorciéndose entre sus dedos. Tampoco pudo verla introduciéndose los genitales en la boca. No pudo enterarse de que este era el único ritual que podía complacerla.

\section{1}

DI:I. ()I)I() AI. AM()R

El primer producto del espiritu es el arre'pentimicento; despuese, el horror de si mismo.

Fi:RNANion SAvATI:R

Miles de ideas revoloteaban en su cabeza. Fslaba confundida, alonlada, sin saber cómo o porqué estaba ahí con él, el lipo más antipálico y mal oliente que había conocido. Sus amigos estaban al lanto del malestar eslomacal que le provocaba el sólo hecho verlo, escucharlo o sentir su respiración. Incluso ellos — sin conocerlo- lo odiaban profundamente. I 0 imaginaban con sus ínfulas de sabelotodo, su reloj de calculadora, su lorpeza a llor de piel, su olor a jabón baralo y su porte que era una mezcla de cura y militar. Lo consideraban insoporlable, antipático y puritano. Suficiente para despreciarlo. Ella les había conlagiado ese desprecio; Io había cultivado día a día, semana a semana; había asumido como un reto personal el que todos supieran que él era menos que una piltrafa, que era 
- como a ella le gustaba decir- un perdedor. En su cabeza se mezclaban confusamente recuerdos de cuando hablaron la primera vez, de lo ridículo que le parecieron sus gestos e insinuaciones, de su mal gusto para vestirse, de lo que chocante que le resultó el orden en su oficina. También vino a su mente la primera invitación que él le hizo, su tacañería y su descortesía. Esslaba segura de que era por eso que lo detestaba. Era por eso que no lograba entender por qué estaba desnuda a su lado contemplando su cuerpo.

IV

Manana DI: JUl.IO

La piel es azafrán al sol tostado, son de gacela los sedientos ojos.

- Eise dios que la hizo, ¿cómo pudo dejar que lo dejase? ¿listaha ciego?

-No e's hechura de ciego e'se prodigio: e's mujer y e's sinuosa cenredadera.

Orinvio Pal

Todavía estaba vivo en su memoria el recuerdo de aquella mañana de julio junto a ella. Había visto sus pechos redondos y firmes, sentido su calor y respirado su olor. El temblor de su cuerpo lo había conmovido. Su mirada no le inspiraba más que una sed de ternura y unos deseos irrefrenables de penetrar en el misterio de sus inmensos ojos negros. La tuvo tan cerca que pudo escuchar los latidos de su corazón; la recorrió con la vista, desde la punta de sus dedos hasta la última hebra de su pelo. No fucron necesarias las palabras, pues el silencio era el mejor tributo a ese cuerpo-su cuerpo- que imponia su presencia en el espacio que ambos ocupaban. Estaban los dos, es cierto, pero ella lo dominaba todo; había llenado de encanto aquel lugar que de ahora en adelante sería sólo de ella. Ouiso tenerla cerca de nuevo. Ouiso revivir aquellos instantes fugaces en los que la creyó suya. Tuvo miedo del olvido: de olvidar su olor y su mirada, el color de su piel y el ritmo de su andar. Se sintió perdido. No tuvo más remedio que refugiarse en su memoria, que le ofrecería los hilos con los cuales tejer los recuerdos de aquella mañana lluviosa de julio, cuando la tuvo delante de sí completamente mojada y tiritando de frío.

Cinco cuentos inconclusos (más) 


\section{$\mathbf{V}$ \\ EI. CUENTISTA \\ Cómo apoyaste tu cabeza sohre mis caderas; cómo dulcemente \\ te volviste hacia mi \\ y me abriste la camisa sobre el pecho para hundir tu lengua hasta llegarme al corazón desnudo. \\ W $\wedge$ i. W WIITMAN}

Acostumbrada a salirse siempre con la suya, no alcanzaba a entender porqué esta vez sus encantos habían fallado. Se ufanaba del dominio que ejercía sobre los hombres que la rodeaban, de su capacidad de manipularlos, de hacerlos sentir importantes o meras piltrafas. Desde pequeña había sido consciente de sus encantos, la picardía de su risa y la intensidad de su mirada. En la adolescencia, un cuerpo torneado y firme se convirtió en su mejor arma. Su piel dorada era el complemento perfecto de ese cuerpo codiciado pero siempre inalcanzable. É lo sabía, sabía de la vocación de ella para seducir y manipular. También sabía que todo su capital era la temura infinita que podía ofrecerle. Ilizo su mejor esfuerzo para no ser presa suya. Sentía socavadas sus certezas más firmes. Busció en los libros, pidió consejo a los hombres más sabios, consultó con brujos y curanderos. Nadie pudo decirle nada sobre el nudo que se le hacía en el estómago cuando la tenía ante sí o la sensación de levedad que se apoderaba de su ser cuando su olor a madera de sándalo le llegaba hasia la profundidad de sus pulmones. Tenía que hacer algo y pronto, aunque no sabía exactamente qué. De momento, no se le ocurrió otra cosá continuar escribiéndole cuentos. 